Original Article

\title{
LAWSONIA ALBA LEAVES INDUCE APOPTOSIS AND CELL CYCLE ARREST IN B16F10 MELANOMA CELLS
}

\author{
NILANJANA DEB ${ }^{1}$, ANITA HANSDA ${ }^{1}$, SOUMYASREE DUTTA ${ }^{2}$, ASHOK PATTANAIK ${ }^{2}$, SHILA ELIZABETH BESRA ${ }^{*}$ \\ ${ }^{1}$ Cancer Biology and Inflammatory Disorder Division and Central Instrumentation Facility, CSIR-Indian Institute of Chemical Biology, 4, \\ Raja S. C. Mullick Road, Kolkata 700032, West Bengal, India. ${ }^{2}$ Birla Institute of Technology Mesra, Ranchi \\ Email: shilabesra@iicb.res.in
}

Received: 29 Dec 2017 Revised and Accepted: 05 Apr 2018

ABSTRACT

Objective: The present study was designed to investigate the anti-melanoma activity of the ethyl acetate fraction of Lawsonia alba lam leaves (ELA) against B16F10 cells.

Methods: Cytotoxicity of ELA on B16F10 cells was determined by MTT assay and supported with the morphology of apoptotic and necrotic cells under phase-contrast microscope, fluorescence microscopy with AO/EtBr, confocal microscopy with PI, Agarose gel electrophoresis and Annexin VFITC/PI staining, mitochondrial membrane potential and cell cycle arrest by FACS was also performed on B16F10 cells.

Results: Cytotoxic effect of ELA on B16F10 melanoma cell was confirmed by MTT assay with an IC 50 value of $14.10 \mu \mathrm{g} / \mathrm{ml}$. Morphological study showed arrays of both the nuclear changes including chromatin condensation and apoptotic body formation indicating that the treatment with ELA and 5-Fluorouracil (standard) causes apoptotic changes in the melanoma cells compared to the untreated control. Agarose gel electrophoresis study showed fragmented DNA in the form of ladder. The depolarization of mitochondrial membrane potential was confirmed. Flow cytometric analysis showed appreciable number of cells in early apoptotic stage. The cells were arrested mostly in G0/G1 phase of cell cycle.

Conclusion: Ethyl acetate fraction of Lawsonia alba L. leaves possesses potent apoptotic activity against B16F10 cells.

Keywords: Lawsonia alba, Cancer, Melanoma, Apoptosis

(C) 2018 The Authors. Published by Innovare Academic Sciences Pvt Ltd. This is an open access article under the CC BY license (http://creativecommons.org/licenses/by/4.0/) DOI: http://dx.doi.org/10.22159/ijpps.2018v10i5.24526

\section{INTRODUCTION}

Cancer is the cell proliferation independent of growth factor regulation with apoptosis resistance and angiogenesis, leading to the disruption of homeostatic condition therapy to tumorigenesis. One of the forms of cancer i.e. malignant melanoma of the skin is the most frequent cause of mortality from skin cancer and approximately $20-25 \%$ of patients with malignant melanoma die of metastatic disease. Melanoma is an aggressive and refractory cancer derived from melanocytes [1]. The incidence of melanoma has been continuously increasing worldwide and becoming a huge public health issue [2]. The standard means of treating melanoma include surgery, radiation therapy, and chemotherapy [3]. (The treatment of melanoma disease largely depends upon early diagnosis [4]. Drug resistance in melanoma mainly occurred through dysregulation of apoptosis, whereas drug transport, detoxification, and enhanced DNA repair may also exert a function [5]. Henceforth, induction of apoptosis deliberated the major target of anticancer chemotherapeutic strategies for melanoma [6].

Lawsonia alba (Lythraceae) commonly known as Henna is widely known for treating various ailments in folklore medicine. Essentially, it is a very common plant with flourishing medicinal properties including anti-microbial [7], antimalarial [8]. Our previous study on $L$. alba reported its hepatoprotective effects along with anti-oxidant property [9]. Amino derivatives of lawsone and lapachol were identified, showing the cytotoxicity against Ehrlich carcinoma and human K562 (leukemia cells). Henna when applied topically on the back skin in the UV-B initiated/TPA promoted and per-oxy-nitrite initiated/TPA promoted mouse skin carcinogenesis models antitumor activities [10]. In this study, we investigated the effects of Lawsonia alba leaves in melanoma cells because of its increasing incidence and high fatality rate for skin tumors. The present investigation ELA is an approach to study the apoptosis-inducing activity of the active fraction from Lawsonia alba leaves against B16F10 melanoma cell lines.

\section{MATERIALS AND METHODS}

\section{Chemicals and reagents}

DMEM, fetal bovine serum(FBS), trypsin (Gibco, USA), 5-Fluorouracil (Sun Pharma), penicillin-streptomycin (Biowest, Germany), gentamycin (Nicholas, India), HEPES, L-glutamine, MTT, acridine orange, ethidium bromide, agarose (Puregene), proteinase $\mathrm{k}$ (SRL), Annexin-V FITC (apoptosis kit), RNase, Propidium Iodide, JC-1 (Sigma), DMSO, Ethyl acetate (Merck). All other chemicals of analytical grade were procured locally.

\section{Cell line}

B16F10 cells were obtained from the National Facility for Animal Tissue and Cell Culture, Pune, India. The B16F10cells were cultured and routinely maintained in DMEM. The medium was supplemented with $10 \%$ heat inactivated fetal bovine serum (FBS), penicillin (100 units $/ \mathrm{ml})$, streptomycin $(100 \mu \mathrm{g} / \mathrm{ml})$, gentamycin $(100 \mu \mathrm{g} / \mathrm{ml})$ and incubated at $37^{\circ} \mathrm{C}$ in a humidified atmosphere containing 5\% CO2 inside a $\mathrm{CO} 2$ incubator.

\section{Collection and identification of plant specimen}

Lawsonia alba Lam. leaves were collected from Ranchi, Jharkhand and identified by Dr. V. P. Prasad, Scientist-D, Central National Herbarium, Botanical Survey of India, Shibpur, Howrah, West Bengal. The specimen authentication no. is CNH/Tech. П/2014/75/158. The preparation of the plant extract was described previously [9]. The methanolic extract of Lawsonia alba was further fractionated by separating funnel using Ethyl acetate. Removal of the solvent in a rotary evaporator (BUCHI R-200) yielded $750 \mathrm{mg}$ of the ELA fraction.

\section{Cytotoxicity study by MTT assay}

For evaluation of the cytotoxic effect of ELA against melanoma cells MTT colourimetric assay was performed [11]. B16F10 cells in the log phase were cultured in 96-well plate and treated with different concentrations of ELA ( $1 \mathrm{mg} / \mathrm{ml})$ for 24,48 and $72 \mathrm{~h}$. Cytotoxicity was measured using 3-(4, 5-dimethylthiazol-2-yl)-2 and 5diphenyltetrazolium bromide (MTT) assay. Standard drug 5-FU $(0.087 \mu \mathrm{g} / \mathrm{ml})$ treated cells served as positive control [12]. The absorbance of each well was observed at a wavelength of $570 \mathrm{~nm}$ by microplate manager (Reader type Model 680 XR Bio-Rad laboratories lnc.) The IC 50 value of ELA was determined for B16F10 cells. 


\section{Cell morphology assessment}

To investigate the effect of ELA on cell morphology $1 \times 10^{6}$ cells (B16F10) were seeded in DMEM media supplemented with 10\% FBS. $24 \mathrm{~h}$ post adherence, the cells were treated with $\mathrm{IC}_{50}$ dose of ELA and anti-cancer drug 5-Fluorouracil. The cells were then observed under a light microscope (Leica Microscope) at a magnification of 40X.

\section{AO-EtBr staining}

The morphological changes of apoptosis were evaluated by fluorescence microscopy [13]. B16F10 melanoma cells $\left(1 \times 10^{\circ}\right)$ were cultured in coverslip in a small petri plate and allowed to grow for $24 \mathrm{~h}$ and another petri plate was kept as control. After $24 \mathrm{~h}$ cells were treated with $\mathrm{IC}_{50}$ dose of ELA, 5-Fluorouracil and control plate was left untreated. After that plates were kept in a humified atmosphere with $5 \% \mathrm{CO}_{2}$ and $37^{\circ} \mathrm{C}$ temperature for $18 \mathrm{~h}$. After $18 \mathrm{~h}$ the cells adhered to the coverslip were washed with PBS and stained with $10 \mu \mathrm{l}$ of acridine orange and ethidium bromide in a ratio of $1: 1$. Then the coverslips were mounted on clear slides and observed under a fluorescence microscope for the morphological determination of the cells undergoing apoptosis.

\section{Propidium iodide staining}

Propidium iodide stain was used to examine the nuclear fragmentation. B16F10 cells in log phase were treated with $\mathrm{IC}_{50}$ dose of ELA and 5-FU for $24 \mathrm{~h}$. After $24 \mathrm{~h}$ the control and ELA treated cells were harvested and washed with ice cold PBS. The cells were then stained with $10 \mu \mathrm{g} / \mathrm{ml}$ of propidium iodide for $5 \mathrm{~min}$. The cells were mounted on slides to observe the differences in nuclear morphology between untreated and ELA treated B16F10 cells under a confocal laser scanning microscope (Leica TCS-SP2 system, Leica Microsystem, Heidelberg, Germany) installed with an inverted microscope [Leica DM-7RB]. Images for propidium iodide were acquired from argon/krypton laser and UV laser line using $590 \mathrm{~nm}$ long pass filter for propidium iodide for images [14].

\section{DNA fragmentation study}

To confirm the apoptotic mode of cell death, DNA fragmentation assay was performed [15]. B16F10 cells $\left(1 \times 10^{6}\right)$ were treated with $\mathrm{IC}_{50}$ dose with ELA and standard anti-cancer drug 5-FU for $24 \mathrm{~h}$. The harvested cells were washed with PBS and re-suspended in lysis buffer, proteinase-k was added and lysis was initiated by incubation at $50{ }^{\circ} \mathrm{C}$ for $1 \mathrm{hr}$ at $37^{\circ} \mathrm{C}$ overnight respectively. DNA fractionation was done following the general phenol-chloroform fractionation procedure. The isolated DNA samples were mixed with loading dye and subjected to $1 \%$ agarose gel electrophoresis for overnight at $20 \mathrm{~V}$ using ethidium-bromide. DNA fragmentation was observed in UV transilluminator (GENEI, Bangalore Genei Pvt. Ltd.)

\section{Mitochondrial membrane potential by flow cytometry}

B16F10 (1x106) cells were treated with ELA (1/2IC 50 dose and) for $18 \mathrm{~h}$ to assay the mitochondrial membrane potential activity of cell in a flow cytometry. Cells were washed with PBS, pelleted down and dissolved in prewarmed PBS. $200 \mu \mathrm{M} \mathrm{JC}-1$ stain was added and the samples were incubated at $37{ }^{\circ} \mathrm{C}$ for $15 \mathrm{~min}$. Shift in the mitochondrial membrane potential was determined by FACS (Becton Dickinson FACS Fortessa 4 laser Cytometer), fluorescence detector equipped with $488 \mathrm{~nm}$ argon laser light source and $623 \mathrm{~nm}$ band pass filter (linear scale) with the help of BD FACS Diva software (Becton Dickinson).

\section{Apoptosis assay by flow cytometric analysis}

To verify apoptosis in B16F10 treated cells, Annexin V-FITC assay was performed [16]. Flow cytometric analysis was done by performing dot plot assay to investigate the type of cell death induced by ELA. Exponentially growing cells were seeded and exposed to IC $5_{0}$ dose of 5-FU and ELA for $18 \mathrm{~h}$. The cell pellets were washed with Annexin-FITC binding buffer provided in apoptosis kit (Sigma) and stained with propidium iodide. All data were taken by Becton-Dickinson FACS LSR Fortessa 4 laser Cytometer was taken using $488 \mathrm{~nm}$ excitation and band pass filters of 530/30 nm (for FITC detection) and 585/42 nm (for PI detection). Live statistics were used to align the $X$ and $Y$ mean values of the Annexin-V FITC or PI stained quadrant populations by compensation. Data analysis was performed by BD FACS Diva software program.

\section{Cell cycle arrest by flow cytometry}

B16F10 (1x106) cells were treated with 5-FU and ELA (IC 50 dose) for $18 \mathrm{~h}$ to assay the stage of cell cycle arrest in a flow cytometry. Cells were washed with PBS, fixed with cold methanol. Then, they were resuspended in cold PBS and kept at $4{ }^{\circ} \mathrm{C}$ for $90 \mathrm{~min}$. Cells were pelleted down, dissolved in cold PBS, treated with RNase for $30 \mathrm{~min}$ at $37^{\circ} \mathrm{C}$ and stained with propidium iodide and kept in dark for 15 min. Cell cycle phase distribution of nuclear DNA was determined by FACS (Becton Dickinson FACS Fortessa 4 laser Cytometer), fluorescence detector equipped with $488 \mathrm{~nm}$ argon laser light source and $623 \mathrm{~nm}$ bandpass filter (linear scale) with the help of BD FACS Diva software (Becton Dickinson).

\section{Statistical analysis}

The data were analysed statistically using one-way ANOVA followed by Dunnet's t-test. The data were expressed as mean \pm SEM. "P" value less than 0.05 implied significance. Values were expressed as mean ${ }^{*} \mathrm{P}<0.05$, when compared to control.

\section{RESULTS}

\section{Cytotoxic potential}

MTT assay revealed significant reduction in cell proliferation in a time and concentration-dependent manner upon treatment with ELA at the concentration of $10 \mu \mathrm{g}, 25 \mu \mathrm{g}, 50 \mu \mathrm{g}, 100 \mu \mathrm{g}$ and $200 \mu \mathrm{g}$ for 24,48 and $72 \mathrm{~h}$ in B16F10 cell line. The IC 50 value of ELA for B16F10 cell line was found to be $14.10 \mu \mathrm{g} / \mathrm{ml}$.

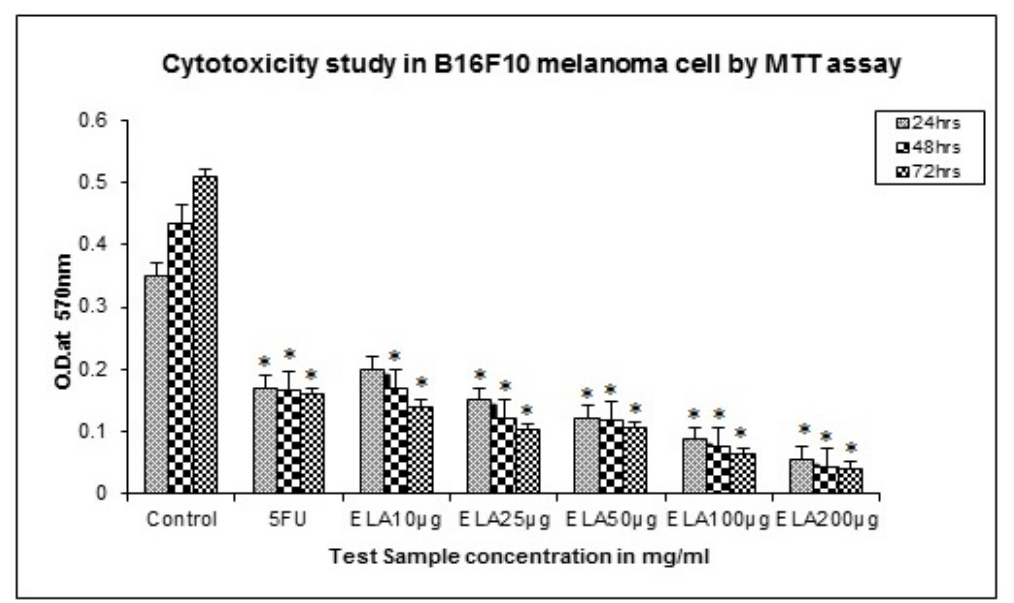

Fig. 1: MTT assay for 24, 48 and $72 \mathrm{~h}$ with different concentrations of ELA on B16F10 cells. The data were expressed as mean \pm SEM. "P" value less than 0.05 implied significance, values were expressed as mean $* P<0.05$, when compared to control 
Cell morphology monitoring by light microscopy

Light microscopic images clearly show membrane disintegration of ELA treated B16F10 cells compared to that of untreated control cells.

\section{Morphological characterization by $\mathrm{AO} / \mathrm{EtBr}$ staining}

Acridine orange and ethidium bromide stained B16F10 melanoma cells revealed nuclear chromatin condensation and apoptotic body formation thereby indicating the occurrence of apoptosis.
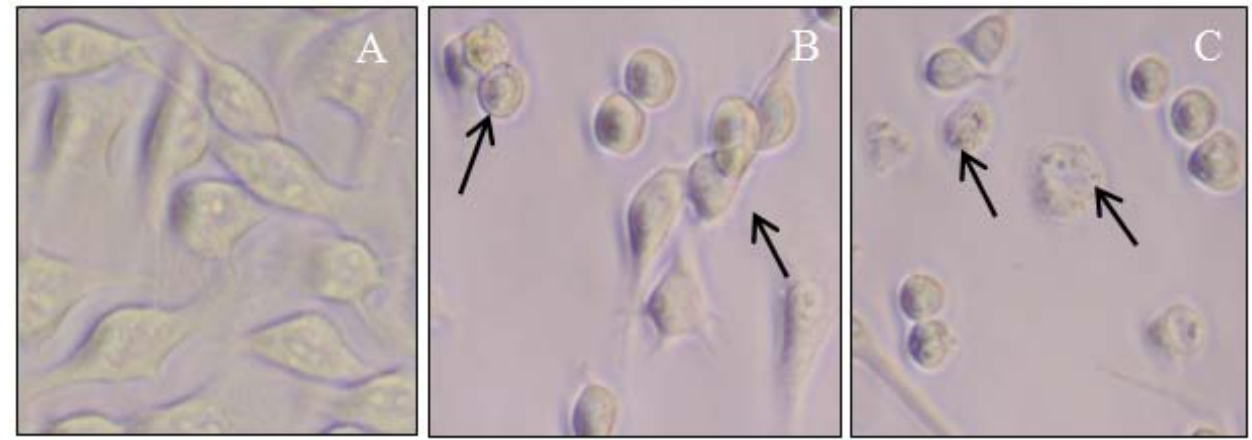

Fig. 2: (A) representslight microscopic images of control cells with intact cell membrane integrity. (B) and (C) represent cells treated with IC50 dose of ELA and 5-FU which show cell shrinkage and membrane disintegration
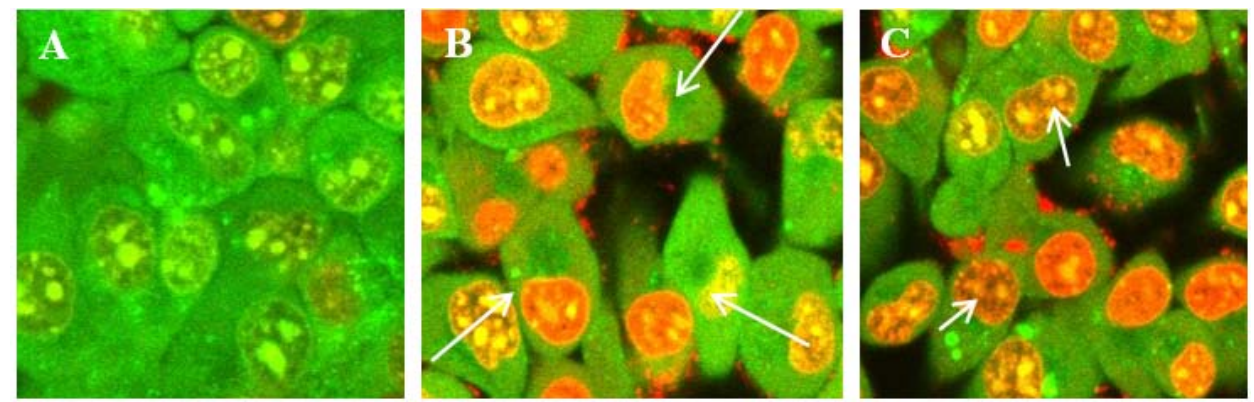

Fig. 3: Fluorescence microscopic images of B16F10 melanoma cells stained with acridine orange and ethidium bromide in 1:1 ratio. (A) represents untreated control cells with intact nuclei that exhibit green fluorescence. (B) and (C) represent cells treated with IC50 dose of ELA and 5-FU. Both Fig. B and C show distinct cell shrinkage, chromatin condensation, nuclear fragmentation and membrane disintegration that are the hallmark of apoptosis

\section{Propidium iodide staining by confocal microscope}

Propidium iodide stained B16F10 skin melanoma cells revealed the presence of apoptotic bodies in the form of nuclear fragmentation in cells as compared to the untreated control cells. Nuclear chromatin condensation and apoptotic body formation indicate the occurrence of apoptosis.
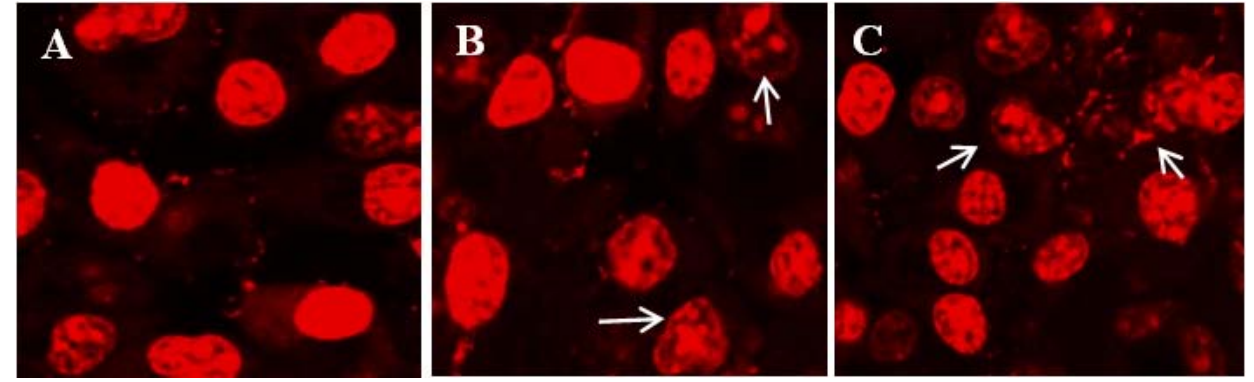

Fig. 4: Confocal microscopic images of B16F10 melanoma cells stained with Propidium iodide. A, B and C represent control, ELA and 5-FU (IC ${ }_{50}$ dose) treated cells. Control cells show intact membrane integrity whereas ELA and 5-FU treated cells show condensed chromatin and fragmented nuclei that confirm the generation of apoptotic bodies

\section{Detection of DNA fragmentation}

The gel pattern of DNA samples isolated from untreated control melanoma cells showed an intact DNA band whereas gel pattern of B16F10 cells treated with IC 50 dose of 5-FU and ELA showed degraded DNA bands in the form of ladder. These observations confirmed apoptosis induction upon treatment with ELA in melanoma cells.

Depolarization of mitochondrial membrane potential

Depolarization in mitochondrial membrane potential was studied by staining treated and untreated cells with JC1 dye. The depolarization 
led to a shift from red to green fluorescence leading to the release of Cytochrome C. A significant shift of $11.7 \%$ and $30.2 \%$ in the mitochondrial membrane potential from red to green fluorescence was observed when B16F10 cells were treated with the $1 / 2$ IC $_{50}$ dose and $\mathrm{IC}_{50}$ dose of ELA for $18 \mathrm{~h}$ respectively.

\section{Detection of apoptosis by flow cytometric analysis}

For the detection of apoptosis by flow cytometric analysis, double labelling technique, using Annexin V FITC and propidium iodide, was utilized. Lower left (LL) quadrant (Annexin V-/PI-) depicted the population of live cells, lower right quadrant (LR) (Annexin V+/PI-) was regarded as the cell population at early apoptotic stage, upper right (UR) quadrant (Annexin $\mathrm{V}+/ \mathrm{PI}+$ ) represented the cell population at late apoptotic stage and extreme upper right (UR) and upper left (UL) quadrant (Annexin V-/PI+) was considered as necrotic cell population. Flow cytometric data analysis revealed that after treatment with $1 / 2$ IC $_{50}$ dose and IC 50 dose of ELA for $18 \mathrm{~h}$, $11.9 \%$ and $16.4 \%$ B16F10 cells were in the LR quadrant compared to $4.2 \%$ control cells indicating early apoptosis.

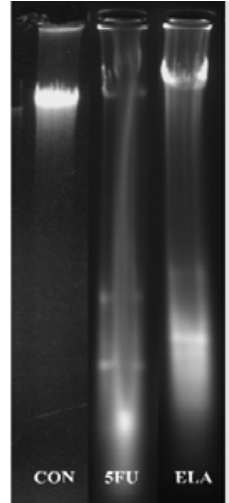

Fig. 5: DNA fragmentation by Agarose gel electrophoresis assay. Lane 1 indicates control cells, lane 2 and 3 indicate 5-FU and ELA treated B16F10 cells
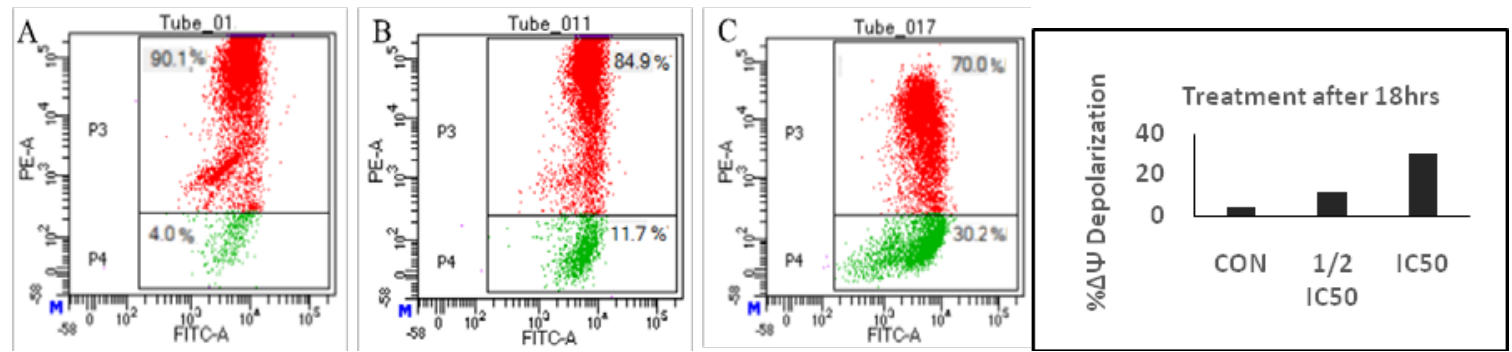

Fig. 6: Flow cytometric analysis of Mitochondrial membrane potential on B16F10 cells in both control (A) and ELA 1/2 IC50 (B) and IC50 treated cells $(\mathrm{C})$ respectively after $18 \mathrm{~h}$ treatment. A significant shift of $11.7 \%$ and $30.2 \%$ from red to green fluorescence was observed
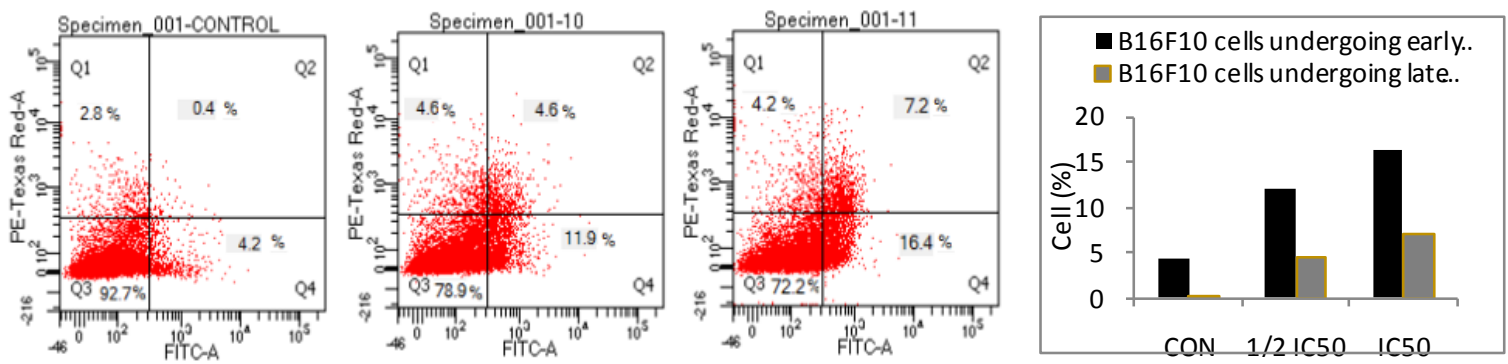

Fig. 7: Detection of apoptosis by Flow cytometric analysis. Control, ELA $1 / 2$ IC50 and IC50 dose treated cells after $18 \mathrm{~h}$ treatment. Staining was done with Annexin V FITC and Propidium iodide. Dual parameter dot plot of FITC-fluorescence (x-axis) vs. PI fluorescence (y-axis) shows logarithmic intensity

\section{Cell cycle arrest by flow cytometric analysis}

Flow cytometric analysis of B16F10 cells when treated with $1 / 2 \mathrm{IC}_{50}$ and $\mathrm{IC}_{50}$ dose of ELA for $18 \mathrm{~h}$ revealed a peak change in the G0/G1 phase. DNA content of $59.8 \%$ and $63.3 \%$ were obtained for $18 \mathrm{~h}$ respectively in G0/G1 phase. These results confirmed ELA treatment arrested cell cycle mostly at G0/G1 phase.
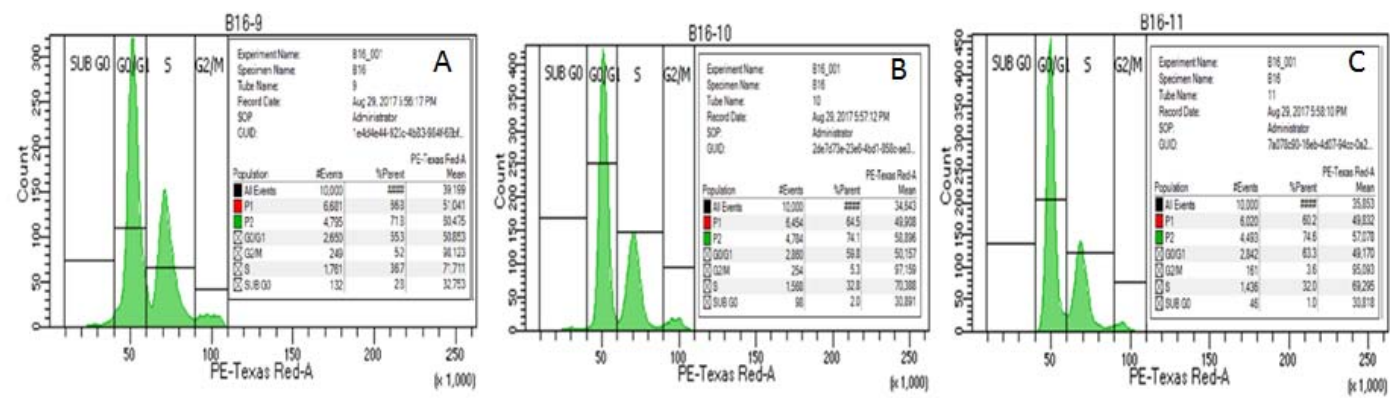

Fig. 8: Flow cytometric analysis of cell cycle phase distribution in control and ELA $1 / 2$ IC $_{50}$ (B) and IC50 treated cells (C) after $18 \mathrm{~h}$ treatment. Histograms represent various contents of DNA with the actual number of cells ( $x$-axis denotes the fluorescence intensity of PETexas red and y-axis denotes count) 


\section{DISCUSSION}

Several natural products and their analogues have been identified as potent anti-cancer agents and the identification of anti-cancer property of various plants is being unravelled in a significant manner. Our results clearly indicated that Ethyl acetate fraction of Lawsonia alba leaves (ELA) exert cytotoxicity on B16F10 melanoma cells through apoptosis. Its anti-melanoma effect was also compared with 5-Fluorouracil, a standard anti-cancer drug. ELA renders anticancer property against B16F10 cells which were supported by the morphological studies and depolarization of the mitochondrial membrane potential thereby leading to apoptosis. These outcomes represent reliable evidence supporting the administration of ELA in melanoma treatment in vitro.

MTT assay revealed a significant reduction in cell proliferation in a time and concentration-dependent manner upon treatment with ELA in B16F10 cell line. The IC 50 value of ELA for B16F10 cell line was found to be $14.10 \mu \mathrm{g} / \mathrm{ml}$. (fig. 1) under phase contrast microscope, the cells in the control group were observed to be spindle-shaped, in close contact with neighbouring cells, and adhered to the surface (fig. 2). Post-treatment with ELA, there was a change in the morphology marked by cell shrinkage, with rounded or irregular cell outlines and many vacuole-like structures in the cytoplasm (fig. 1B, C). Morphological changes of B16F10 cells treated with ELA and 5-FU for $24 \mathrm{~h}$ at $\mathrm{IC}_{50}$ were also analyzed by dual acridine orange/ethidium bromide (AO/EB) fluorescent staining. Acridine orange and Ethidium bromide are two cationic fluorescent DNA intercalating dyes. AO stains the viable cells green whereas EtBr stains the apoptotic cells orange, fragmented green nucleus represent early apoptotic cells, and orange/green dots of condensed nuclei indicate late apoptosis [17]. Cells treated with ELA upon $\mathrm{AO} / \mathrm{EtBr}$ staining exhibited characteristic changes of apoptosis e. g. cell shrinkage, nuclear condensation, fragmentation and formation of apoptotic bodies (fig. 3). In order to aid the nuclear visualization, cells were stained with PI and nuclear morphology changes were observed under the confocal microscope. Cells treated with ELA showed nuclear margination and chromatin condensation, membrane blebbing, nuclear fragmentation and membrane loss (fig. 4). Fragmentation of chromatin to units of single or multiple nucleosomes that form the nucleosomal DNA ladder in agarose gel is an established hallmark of programmed cell death or apoptosis [18]. DNA fragmentation as detected by agarose gel assay suggests induction of apoptosis following exposure to ELA (fig. 5).

JC-1 is a novel cationic carbocyanine dye that accumulates in mitochondria. The loss of mitochondrial membrane potential is a hallmark of apoptosis. In healthy cells, the dye stains the mitochondria bright red. The negative charge established by the intact mitochondria membrane potential allows the lipoliphic dye bearing a delocalized positive charge, to enter the mitochondrial matrix where it accumulates. In apoptotic cells, the mitochondrial membrane potential collapses, and the JC- 1 cannot accumulate within the mitochondria. In these cells, JC-1 remains in the cytoplasm in a green fluorescent monomeric form. Apoptotic cells showing primarily green fluorescence are easily differentiated from healthy cells which show red fluorescence. JC-1 staining of B16F10 cells treated with ELA shows a significant shift in the transmembrane potential from red to green fluorescence. Hence, our data suggest a change in the transmembrane potential, thereby triggering apoptosis (fig. 6). Quantitative estimation of cells undergoing early and late apoptosis was performed by Annexin VFITC staining. The translocation of phosphatidylserine molecules to the outer surface of the cell allows determination of apoptosis when Annexin-V labeled with FITC is applied to the cell environment [19]. Annexin V-PI-considered as viable cells, while Annexin V+/PIstaining patterns showed early apoptotic cells; whereas Annexin $\mathrm{V}+$ /PI+ exhibited late apoptotic cells due to a loss of plasma membrane integrity and Annexin V-FITC-/PI+ was considered as necrotic cells $[20,21]$. B16F10 cells when treated with 5-FU and IC ${ }_{50}$ dose of ELA demonstrated cells undergoing early apoptosis (fig. 7). Cell cycle and apoptosis together play an important role in the sensitivity of cancer cells. Cell cycle checkpoints are important regulatory mechanisms that ensure the proper passage of cells through the cell cycle. The G2/M and G1/S checkpoints are critical in maintaining DNA integrity and essential in executing the proper cell cycle events. It was known that loss of regulation of these checkpoints resulted into transformation and progression of cancer cells. The mode of cell death of cancer cells by ELA predominately followed apoptosis. A possible arrest of the G0/G1 phase might have triggered apoptosis (fig. 8).

In conclusion, the present study demonstrated that ELA could inhibit the proliferation of B16F10 cell line in vitro and induce apoptosis by causing a shift in the mitochondrial membrane potential. Therefore, the results from this study provide critically important experimental facts to suggest that ELA may be a potential therapeutic agent for treating melanoma.

\section{CONCLUSION}

Ethyl acetate fraction of Lawsonia alba demonstrated dose-dependent anti-proliferative properties in B16F10 melanoma cells. We also observed membrane blebbing chromatin condensation, membrane loss and DNA fragmentation in the form of the ladder in ELA treated B16F10 cells. The morphological characteristics indicated the induction of apoptosis. Post ELA treatment, the transmembrane potential shift from red to green also triggered apoptosis. Annexin V-FITC staining demonstrated cells undergoing early apoptosis. Cell cycle study observed by flow cytometry revealed a possible arrest of the G0/G1 phase, indicating this phase arrest might have triggered apoptosis. These results have important clinical implications as they suggest commendable anti-proliferative activities against B16F10 melanoma cells. Ethyl acetate fraction of Lawsonia alba can be considered as an effective adjuvant therapeutic agent. Further study of proteins involved in apoptosis will improve our findings and give useful results to establish Lawsonia alba as a novel drug against melanoma.

\section{ACKNOWLEDGEMENT}

The authors would like to thank CSIR-Indian Institute of Chemical Biology, for providing the platform to pursue the research work smoothly. The authors would also like to express their gratitude to Mrs. Banasri Das, Senior Technical Officer and Mr. Binayak Pal, Principal Technical Officer for their constant technical support.

\section{AUTHORS CONTRIBUTIONS}

The corresponding author Dr. Shila Elizabeth Besra, has generated the idea for the experiment and has critically examined and corrected the manuscript. Nilanjana Deb, the first author has conducted the experimental work and written the manuscript. Other authors Anita Hansda, Soumyasree Dutta and Dr. Ashok Pattanaik have helped during the experimental work and in the interpretation of the results. All authors read and approved the final manuscript.

\section{CONFLICT OF INTERESTS}

The authors declare they have no conflict of interest regarding the publication of this paper.

\section{REFERENCES}

1. Markovic SN, Erickson LA, Rao RD. Melanoma study group of the mayo clinic cancer center. Malignant melanoma in the $21^{\text {st }}$ century, Part 1: epidemiology, risk factors, screening, prevention, and diagnosis. Mayo Clin Proc 2007;82:364-80.

2. Vikey AK, Vikey D. Primary malignant melanoma, of head and neck: a comprehensive review of the literature. Oral Oncol 2012;48:399-403.

3. Guevara Canales J0, Gutierrez Morales MM, Sacsaquispe Contreras SJ, Sanchez Lihon J, Morales Vadillo R. Malignant melanoma of the oral cavity. Review of the literature and experience in a peruvian population. Med Oral Patol Oral Cir Bucal 2012;17:206-11.

4. Bhatia S, Tykodi SS, Thompson JA. Treatment of metastatic melanoma: an overview. Oncology 2009;23:488-96.

5. Grossman D, Altieri DC. Drug resistance in melanoma: mechanisms, apoptosis, and new potential therapeutic targets. Cancer Metastasis Rev 2001;20:3-11.

6. Hassan M, Watari H, AbuAlmaaty A, Ohba Y, Sakuragi N. Apoptosis and molecular targeting therapy in cancer. Biomed Res Int 2014. http://dx.doi.org/10.1155/2014/150845 
7. Arun P, Purushotham KG, Jayarani JJ, D Kumari V. In vitro antibacterial activity and flavonoid contents of Lawsonia inermis (Henna). Int J PharmTech Res 2010;2:1178-81.

8. Babili FE, Valentin A, Chatelain C. Lawsonia inermis: its anatomy and its antimalarial, antioxidant and human breast cancer cells MCF7 activities. Pharm Anal Acta 2013;4:203.

9. Dutta S, Deb N, Pattanaik AK, Besra SE. The apoptosis-inducing potential of Lawsonia alba lam. Leaves on hepatocellular carcinoma (Hep-G2) cells along with its anti-oxidant property. Int J Pharm Pharm Sci 2016;8:156-62.

10. Kapadia GJ, Rao GS, Sridhar R, Ichiishi E, Takasaki M, Suzuki $\mathrm{N}$, et al. Chemoprevention of skin cancer: effect of Lawsonia inermis $\mathrm{L}$. (Henna) leaf powder and its pigment artifact, lawsone in the epstein-barr virus early antigen activation assay and in two-stage mouse skin carcinogenesis models. Adv Anticancer Agents Med Chem 2013;13:1500-7.

11. Denizot F, Lang R. Rapid colorimetric assay for cell growth and survival. Modifications to the tetrazolium dye procedure giving improved sensitivity and reliability. J Immunol Methods 1986;89:271-7.

12. Fontes JEN, Ferraz RP, Britto AC, Carvalho AA, Moraes MO, Pessoa C, et al. Antitumor effect of the essential oil from leaves of Guatteria pogonopus (Annonaceae). Chem Biodivers 2013;10:722-9.

13. Jimenez PC, Wilke DV, Takeara R, Lotufo TM, Pessoa C. Cytotoxicity activity of a dichloromethane fraction and fractions obtained from Eudistoma vannamei (Tunicata: Ascidiacea). Comp Biochem Physiol MolIntegr Physiol 2008;151:391-8.
14. Gupta SD, Debnath A, Saha A, Giri B, Tripathi G, Vedasiromoni $\mathrm{JR}$, et al. Indian black scorpion (Heterometrus bengalensis Koch) venom-induced anti-proliferative and apoptogenic activity against human leukemic cell lines U937 and K562. Leuk Res 2007;31:817-25.

15. Walker PR, Kokileva L, LeBlanc J, Sikorska M. Detection of the initial stages of DNA fragmentation in apoptosis. BioTechniques 1993;15:1032-40.

16. Liao PC, Lieu PC. Cell cycle specific induction of apoptosis and necrosis by paclitaxel in the leukemic U937 cells. Life Sci 2005;76:1623-39.

17. Deborah R, Nathaniel BG, David AN, Yuqun GS. A simple technique for quantifying apoptosis in 96 well plates. BMC Biotechnol 2005;5:12.

18. Telford WG, King LE, Fraker PJ. Induction of apoptosis has been a new target for innovative mechanism-based drug discovery. Cell Prolif 1991;24:447-59.

19. Vermes I, Haanen C, Steffens Nakken H, Reutelingsperger C. A novel assay for apoptosis. Flow cytometric detection of phosphatidylserine expression on early apoptotic cells using fluorescein labelled Annexin V. J Immunol Methods 1995;184:39-51.

20. Brauchle E, Thude S, Brucker SY, Schenke Layland K. Cell death stages in single apoptotic and necrotic cells monitored by Raman microspectroscopy. Sci Rep 2014;4:1-9.

21. Dartsch DC, Schaefer A, Boldt S, Kolch W, Marquardt H. Comparison of anthracyclines induced death of human leukemia cells: programmed cell death versus necrosis. Apoptosis 2002;7:537-48. 